\title{
Trial Evaluation of Wireless Info-Communication and Indoor Location-based Services in Exhibition Shows ${ }^{1}$
}

\author{
Adamantia G. Pateli, George M. Giaglis, Diomidis D. Spinellis \\ Athens University of Economics and Business \\ 47A Evelpidon \& 33 Leukados Street, 11362, Athens, Greece \\ \{pateli, giaglis,dds\}@aueb.gr
}

\begin{abstract}
Exhibition shows are essentially information exchange hubs. Their success relies on the quantity and quality of interaction of the involved parties: exhibitors, visitors, and organizers. The introduction of advanced wireless applications in the exhibition industry is a major opportunity for improving interaction and communications, thus leveraging the value proposition of exhibition services. This paper discusses the development and commercial trial of a Wireless Exhibition Guide that employs mobile terminals, wireless networks, and indoor location positioning technologies integrated through a set of software components, to introduce sophisticated information, communication, and navigation services for exhibition environments. Results indicate acceptance of the Wireless Exhibition Guide amongst the stakeholders of the exhibition industry, organizers, exhibitors, and visitors alike, and provide guidance towards the future of portable personalized location-sensitive information systems in information-rich environments, such as museums, conference centers, and art shows
\end{abstract}

\section{Introduction}

Despite the emergence of various electronic business communication and promotion methods over the past years, exhibition fairs continue to rank as the most dynamic and effective sales and marketing tools in existence [1]. In the context of the modern economy, fairs continue to bring together market participants providing a unique opportunity for personal contact and information exchange. Moreover, fairs and exhibitions are "shop windows" offering insights into the latest industrial products and services to business and individual visitors.

As exhibition organizers compete to generate value for their shows, their attention and promotional activities have been concentrating more and more on visitors rather than on exhibitors [2]. Visitor satisfaction has become of strategic importance and has

\footnotetext{
${ }^{1}$ In Panagiotis Bozanis and Elias N. Houstis, editors, Advances in Informatics: 10th Panhellenic Conference on Informatics, PCI 2005, pages 199-210. Springer-Verlag, November 2005. Lecture Notes in Computer Science 3746.

This is a machine-readable rendering of a working paper draft that led to a publication. The publication should always be cited in preference to this draft using the reference in the previous footnote. This material is presented to ensure timely dissemination of scholarly and technical work. Copyright and all rights therein are retained by authors or by other copyright holders. All persons copying this information are expected to adhere to the terms and constraints invoked by each author's copyright. In most cases, these works may not be reposted without the explicit permission of the copyright holder.
} 
led trade fair organizers into pursuing a new strategy described by the term 'visitor orientation'. Towards implementing this strategic goal, one of the things exhibitors bear in mind, while designing and setting up their show, is the need to accomplish the 'extended-stay visit' [3]. Exhibitors are naturally interested in making visitors stay at their corporate booths as long as possible. To this end, traffic flow engineering is typically employed. Self-guided tours based on various technological means (ranging from CD-ROMs to portable computing devices) are used to direct visitors at a desired pace throughout the show. In addition, firms try to notify visitors about presentations taking place at different times of the day, so as to extend their stay in the exhibition place. At the same time, exhibitors must provide something to be remembered; this trend is referred to as 'experiential exhibiting' [4]. Technology can assist in making a sophisticated and impressive presentation of the exhibition products' unique selling points.

\section{The Wireless Exhibition Guide}

Drawing on the experience of previous research and commercial efforts on providing wireless services in exhibition [5, 6], museum [7] and conference settings [8], and having identified a set of technological solutions allowing for efficient peer-to-peer wireless communication and positioning of increased accuracy, a European-wide development and research team, with the participation of a number of ICT providers (Intracom Hellenic Telecommunications and Electronics Industry S, L.M. Ericsson A/S, Elisa Communications Corporation, Pouliadis Associates Corporation, Space Systems Finland Ltd.), research institutes (Research Center of Athens University of Economics and Business, Helsinki University of Technology) and exhibition venue owners (The Finnish Fair Corporation, ROTA Ltd.), initiated a research project, partially funded by the European Commission, to design and develop a Wireless Exhibition Guide (WEG). The WEG aimed to exploit the technological opportunities arising from evolution in the areas of wireless networks and indoor positioning technologies [9] to provide value-added services supporting the professionals and customers in the exhibition industry in a context-aware manner [10].

The following sections discuss in brief several aspects of the Wireless Exhibition Guide development, such as the technology applied (sub-systems and infrastructure), a usage scenario indicative of the services provided for the three stakeholders of the exhibition sector (exhibition organizers, exhibitors, and visitors), and the results from the system's testing and user evaluation in a real exhibition event.

\section{A WEG Use Scenario}

The scenario involves Philip, a visitor in the "Mobile Expo" organized by Finnish Fair Corporation (FFC) in Finland, who uses a set of value-added services provided by the WEG application.

Philip enters the exhibition center and passes through the reception. The registration staff of FFC asks for his invitation and the visitor informs them about his online pre-registration. The secretariat asks the visitor if he wishes to use the WEG. After getting all the required information, Philip agrees to download the WEG software to 
his device under the guidance of the FFC technical staff. While he is about to enter the exhibition hall, he meets a colleague, Charles, who is about to register onsite. Philip, who is a leader and moderator of a group comprising of the company's employees, is inviting Charles to become member of the group. After that, Charles gets his device as well, and they go on their different ways. Before splitting, they both ask to view on their devices a personalized and location-aware navigation plan.

Since Philip wishes to locate specific products, he uses his device to locate stands with the specific products on the map. After locating those stands on the navigation plan, he takes the routing advice of his device to get there. As he approaches the stand of interest, he receives alerts for offerings based on his profile as well as targeted promotional spots of certain exhibits from the exhibitors. While wandering through the stands, Philip gets recommendations for specific events as well as common announcements (e.g. the exhibition is about to close). He is visiting 3 or 4 other stands that are in his list, and he follows the exact same procedure with the previous ones.

After being in the exhibition for 3 hours, Philip decides to take a break for a snack or coffee so he moves towards the closest restaurant or rest area by using his navigation plan and routing advice on his device. On his way to the restaurant, he decides to meet with Charles, so he uses the system to track him since they both belong to the same user group. When he manages to position Charles, he sends a real-time message asking him to meet in five minutes in the restaurant area. Before sitting in the restaurant, they connect to the nearest kiosk to get information on their visit trail and movements up to this moment. Before leaving the exhibition center, Philip asks to get information on nearby means of transportation.

While being at home or in the office, Philip gets connected to the Internet, gets access to the WEG software, and downloads the material that he requested through bookmarks, as well as additional promotion material sent either by organizers or exhibitors. Furthermore, replying to the organizers' request, he uses the system to send feedback by giving his response to an online questionnaire.

\section{The Technology Solution}

The Wireless Exhibition Guide technology solution is implemented through a set of software and hardware components. The way in which these are integrated is more thoroughly discussed in prior research works $[10,11]$. This section briefly discusses the WEG technology solution in terms of system architecture (Fig. 1).

The core component of the Wireless Exhibition Guide system is the application server, which is responsible for handling user requests and realizing the relevant application logic (e.g. navigation assistance, personalized recommendations, "bookmarking" capability, business cards exchange, monitoring of mobile terminal locations, content management). The application server receives user requests via either the Internet or the wireless network installations of the exhibition center. Two wireless networking technologies $(802.11 \mathrm{~b}$ WLAN and Bluetooth) are employed and tested to provide wireless access to visitors, exhibitors, and exhibitor organizers within the exhibition boundaries.

The delivery of location-based services and information (i.e. targeted messages [12], bookmarking, virtual trail) is enabled via two indoor positioning technologies; WLAN-based Positioning System and Indoor GPS System. WLAN-based Positioning is based on the WLAN infrastructure, which is also used for transferring data to and 
from the users. Indoor GPS constitutes a rather innovative positioning solution developed by Space Systems Finland Ltd. The indoor GPS system includes: a) a number of ground transmitters, pseudolites (pseudo-satellites) that emulate the signal of GPS satellites and replace GPS in the exhibition environment, b) a set of reference receivers that are used for signal integrity provision and synchronization of the pseudolites signals, and c) the Master Control Station (MCS) running the control software for providing monitoring, configuration, and control of the whole system.

The wireless devices that enable access to the application server and delivery of the WEG navigation, communication and information services include Personal Digital Assistants (PDAs) and laptops. Visitors use PDAs to make bookmark requests, receive exhibition content, and routing information. During the trial operation of the system, a specific PDA (iPAQ 3870) was selected to test visitors' services. Nevertheless, other models of PDA devices can as well be used provided that they are WLANenabled and have a free PCMCIA socket for a GPS receiver. Visitors can also use laptops for preparing their visit before the exhibition and review their visit after it. Exhibitors and exhibition organizers can use wireless connected laptops to receive statistics, get real-time notifications, and submit exhibition content.

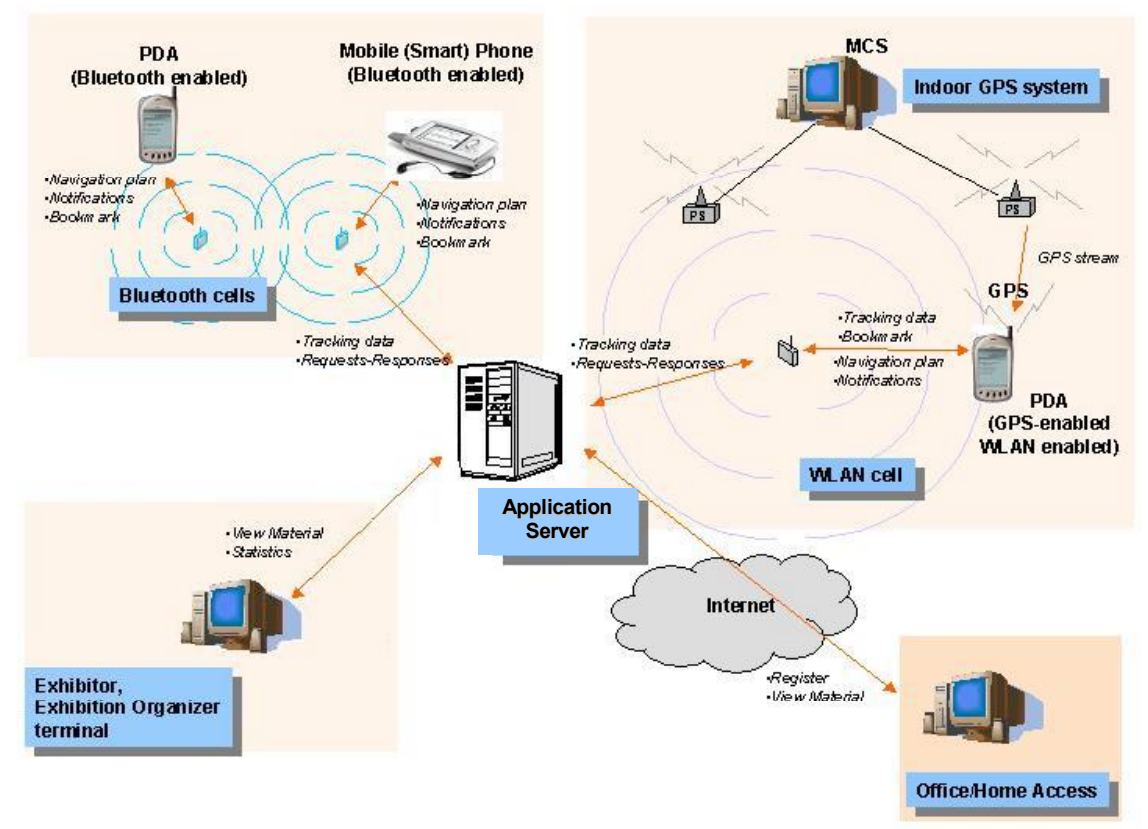

Fig. 1. Technical Architecture of the Wireless Exhibition Guide

\section{Trial Design}

The trial operation of the WEG prototype took place in the FFC Exhibition Center, Helsinki, Finland on 18-19 March 2004 during the ViiniExpo (The Wine Exhibition). The trial consisted of two stages. Stage I included testing of the primary technologies 
applied first in isolation and then in integration, while Stage II concerned the evaluation of the system's services from the end-user perspective. The whole paper is primarily focused on Stage II (user evaluation), the methodology employed and results. Regarding Stage I, due to space restrictions, we considered it important to include information on only the positioning accuracy achieved by the two principal wireless technologies (WLAN-based and Indoor GPS).

\section{End-User Evaluation Methodology}

The principal objectives set for the evaluation of the WEG included:

a) Collecting data on users' attitude towards the future use of the system,

b) Assessing overall experience and satisfaction with the WEG services.

A total of 17 persons were involved in the evaluation process of the WEG prototype: 12 visitors, 3 exhibitors, and 2 organizers. They were all interviewed and then given an evaluation form to fill in.

The trial, which lasted two days, gave emphasis on visitors' experience of the system with the use of PDAs. In addition, the trial focused on testing the delivery of position services, which had been considered as the most important feature of the Wireless Exhibition Guide during the user requirements phase. Table 1 indicates which validation methods applied in each user group.

Table 1. Evaluation Methods applied per test-group

\begin{tabular}{|l|c|c|c|}
\hline $\begin{array}{l}\text { Evaluation } \\
\text { Methods }\end{array}$ & Visitors & Exhibitors & Organizers \\
\hline Test Group & & & \\
\hline- Test Tasks & $\mathrm{X}$ & $\mathrm{X}$ & $\mathrm{X}$ \\
\hline- Interview & $\mathrm{X}$ & $\mathrm{X}$ & $\mathrm{X}$ \\
\hline $\begin{array}{l}\text { - Ebservation } \\
\text { Form }\end{array}$ & $\mathrm{X}$ & $\mathrm{X}$ & $\mathrm{X}$ \\
\hline- Demonstration & $\mathrm{X}$ & & \\
\hline
\end{tabular}

In practice, visitors performed a set of test tasks, while being under observation. The evaluation expert went through all tests with users playing the role of moderator. Visitors were asked to perform 8 tasks in total. They were also asked to think aloud while interacting with the system. When all test tasks were completed, the moderator asked visitors some general questions and then left them some free time to fill in an evaluation form. Exhibitors performed about 10 test tasks in total. Before any task, they were shortly introduced to the WEG system from the visitor's side in order to be able to imagine how their customers interact with the system. Also exhibitors were told to think aloud and fill in an evaluation form being tailored to their interaction with the system. For organizers, there were no test tasks available. Instead, the whole functionality of the WEG system was demonstrated to them, so that they evaluate it from the viewpoint of the candidate buyer of the software. In practice, organizers were asked to evaluate the system from all the three user groups' side. 


\section{Evaluation Tool}

Following, we present the main sections, which correspond to the primary evaluation criteria, of the delivered evaluation forms.

- User Interface \& Performance - Users are asked whether the User Interface (fonts, color, position, menus, forms) is aesthetically pleasant and exciting, as well as whether the systems is easy to learn, is easy to operate and has satisfactory performance speed.

- Value of Services. For each essential and innovative service, its perceived value is measured. The formal definition of usefulness is "the degree to which a person believes that using a particular system would enhance his or her job performance" [13]. In the exhibition context, the system should enhance the visiting and communication experience of visitors, the communication and promotion performance of exhibitors and the management and monitoring ability of organizers in a manner complementary to curren practices.

- General Attitude Towards the System. Issues like trust and willingness to use are faced in this part. Users are asked to declare their willingness to use the system in the future. However, the Perceived Ease of Use and Perceived Usefulness are considered by the TAM construct as the key factors influencing the users' behavioral intention and actual use of the system [14]. Users are also asked to state their intention to pay for getting the systems' services as well as the price level they can afford for getting the system's services.

- Overall mobile experience and satisfaction from the system. Questions in this part examine the overall experience from using mobile devices and mobile technologies along with the overall satisfaction of using a new system to support visiting experience [15]. Users are asked to compare their experience to the one gained during exhibition visits in the "traditional" way.

\section{Trial Results and Business Implications}

Due to the restricted size of the test sample, the data collected from the three user groups via observation, interview and evaluation forms could not be analyzed with quantitative statistical methods. Instead, qualitative methods are employed to stress the main strengths and weaknesses of the system, as they were verbally expressed but also coded in the delivered questionnaires.

\section{End-User Evaluation Results}

Test users who played the role of visitors were very keen about the features of the WEG. Some of them rated the system very high, despite the usability problems and the relative instability of the system during the trial. Others were not so happy with their visiting experience. This was naturally reflected in their comments (interviews and forms) and can be explained by their high expectations from the system. Conversely, for those whose expectations were not so high, technical problems that were presented were not insurmountable. Regarding the positioning services that were provided, these were seen as key drivers for the use of the software. In addition to posi- 
tioning features, communication features were also found interesting and useful. Especially the message service was considered to be an advantageous feature. However, users were not happy with the way in which these services were delivered, since communication features suffered from usability problems. Some key statements/ suggestions of visitors are presented in Table 2.

Table 2. Visitors' Suggestions for Improvement

"The real added value concretizes in bigger exhibitions (CEBIT,
COMDEX, etc.)"
"There should also be some features that show users' location and their
direction when they move"
"If users can choose the most interesting stands before, those stands
should be seen in different color on map when entering to exhibition
hall"
"As, in the next two or three years, almost everyone will have a smart
phone (or a similar mobile device), it would be useful to be able to use
the Wireless Exhibition Guide through smart phones as well".

Visitors were keen to use position based services in future, and they were also "happy to see the glimpse of WLAN in action" for the very first time. The positive attitude towards the system can be analyzed in the user needs context as they were set at the first place. In the case of visitors, it can be said that apart from some existing needs raised from the exhibition visiting experience, there were also needs which emerged only during the WEG use experience. General requirements like to know where you are, to locate companies and stands as easily as possible and to share your experiences with others can be considered "universal needs". The WEG satisfied this kind of needs in a satisfactory level, and this is why the majority of visitors involved to test appreciated these features. On the contrary, needs like "to avoid the information overload" and "to get just the information user wants at particular time/place" were clearly born by the usage of the WEG system. Namely, the system's ability to offer limited or regulated information based on user's location to avoid unnecessary actions (like scrolling long lists of exhibitors), were features which visitors found surprisingly useful. This is the result of the technology's ability to create new needs, not just satisfy the existing ones.

Test users in the role of exhibitors were first introduced to the features visitors used through a PDA. After this short demonstration, exhibitors were asked to conduct ten test tasks designed only for them. The expectations of exhibitors were quite neutral. Maybe this was one reason why they were considerably happy with the elements of the WEG. They identified a number of very useful and value-added tools provided by the system. Their specific comments are quoted in Table 3. 
Table 3. Exhibitors' Suggestions for Improvement

- The Analyzing and Reporting Tool was found "Useful tool to know what kind of individuals or groups of individuals have been visiting the exhibition or stands" and "Very valuable tool for after-sales service".

- The Virtual Business Cards facility was considered a value-added service because "It can consist of more important information of a company and its products than traditional business cards or brochures".

- The Communication tool was characterized as "a very handy tool for sending messages to certain individuals characterized by some attributes vital to exhibitor's own interests".

Overall, exhibitors were also quite satisfied with the elements and features of the WEG. In more specific terms, the ability to use tools for analyzing and reporting visitors was found as a new useful and quite valuable service. The identified usability shortcomings somehow affected the overall experience, but still exhibitors saw the whole service as a good tool that could generate added value in their exhibition experience.

There were two exhibition industry organizations involved in the trial, Finnexpo and ROTA. Representatives of those companies were first shown the visitor's part of the system (with PDA in the exhibition hall). After this short demonstration, they were asked to use the system via PC at the same place where exhibitors did their tasks (the office set-up). Some of the WEG services, such as the online exhibitor catalogue and the pre-registration facility, were already offered by the exhibition organizers though one or more web-based information systems. However, the very added value of the WEG was the fact that organizers did not have just one system in use that would incorporate all valuable features. Thus, the system could even, in principle, somehow replace or supplement their current business practices and systems. This was the main reason why organizers also liked the WEG. But at the same time, they were skeptical about the ability of the system to integrate with their legacy systems. Despite this skepticism, several very useful and precious features were found. Especially tools for creating and viewing questionnaires, as well as extracting statistical reports, were seen very handy in order to replace their existing practice of getting feedback from visitors. However, "if the system could generate real-time information, such as how many visitors are on-line at a particular time, which stands are the most popular ones, then it would offer even more positive feedback to organizers".

Organizers were the most significant test group. Their high requirements and expectations from the use of the WEG system were due to having already part of the WEG services in place through their legacy systems. However, organizers lacked an integrated system with all essential features incorporated. This was considered as the core value that the WEG system generated for exhibition organizers. Moreover, navigation and positioning services were also seen as critical source of value, since the organizers do not currently offer such services in their exhibition events. 


\section{Positioning Accuracy}

The achieved positioning accuracy of the visitors is described as a part of the evaluation results, since it affects the user experience significantly and is referred frequently in the evaluation results by the test users. There were two separate positioning subsystems in operation, but it was transparent to the main server which (either one or both) of them was in use at a time.

\section{iGPS positioning subsystem}

The pseudolite system trials were conducted in a different hall of the Finnish Fair Expo Center. Although the actual usability tests were conducted in Hall 4, where the actual Wine exhibition was taking place, the pseudolite tests were performed in another exhibition hall (Hall 2) (Fig. 2). This was due to the lack of small and unnoticeable end-user receivers that could be used in a transparent way in the exhibition place.

The test results showed that the pseudolite system is capable of providing very good positioning accuracies in an indoor environment. In the beginning of the project, it was estimated that an accuracy of 1 meter would serve the needs of an exhibition application. During the tests, we showed that sub-meter, and even sub-decimetre, accuracies can be acquired using the pseudolites. Specifically, the achieved positioning DRMS (distance root mean square) for 2-dimensional positioning $(\mathrm{x}, \mathrm{y})$ was $0.06 \mathrm{~m}$ and $0.24 \mathrm{~m}$ for 3 -dimensional positioning $(\mathrm{x}, \mathrm{y}, \mathrm{z})$. Although the current system is not feasible for real exhibitions due to the inconvenient size of the end-user receiver, discussions with receiver manufacturers revealed that small and efficient receivers should be available by early 2005 .

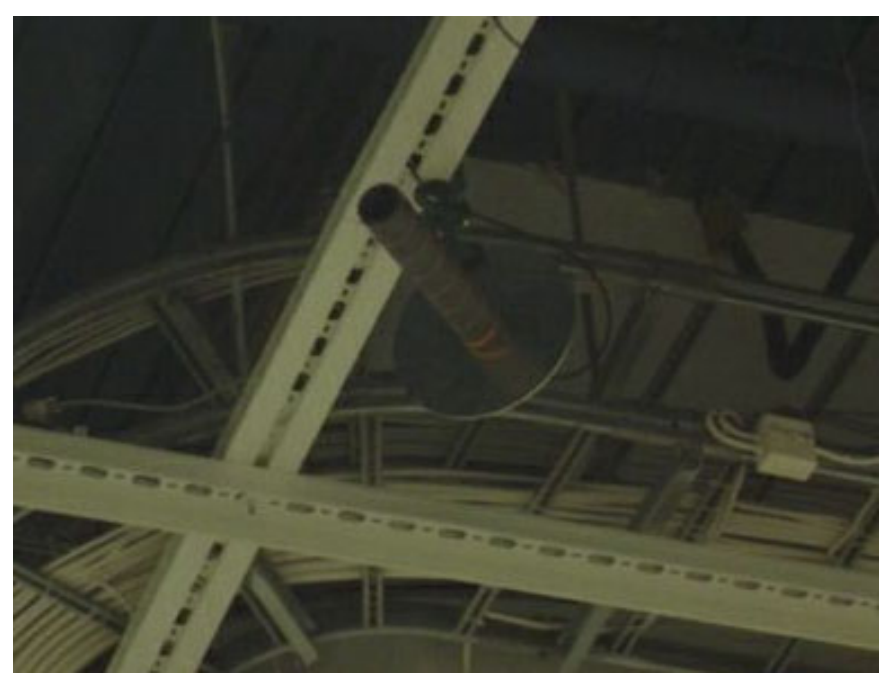

Fig. 2. The pseudolite antenna attached to the ceiling of the Exhibition Hall 2 


\section{Wireless LAN positioning subsystem}

The wireless LAN access network covered the whole FFC Exhibition Centre, and thus the WLAN positioning system was available in both halls, the mock-up site in Hall 2 as well as the actual exhibition site in Hall 4. The positioning system only needed the installation of the positioning client software at the client device side. Due to this practical reason, the user tests of the final trial evaluation were performed only by using the WLAN positioning system and standard Compaq iPAQ's with WLAN accessibility in Exhibition Hall 4.

The achieved accuracy in the un-optimized network of the FFC Exhibition hall (Fig. 3) was fair: 4.2 meters in average. This was achieved with just a basic WLAN access network, consisting of only 2 access points per hall and without any optimization to the access point settings. The average accuracy is fairly good, but occasional errors of more than 10 meters appeared every now and then.

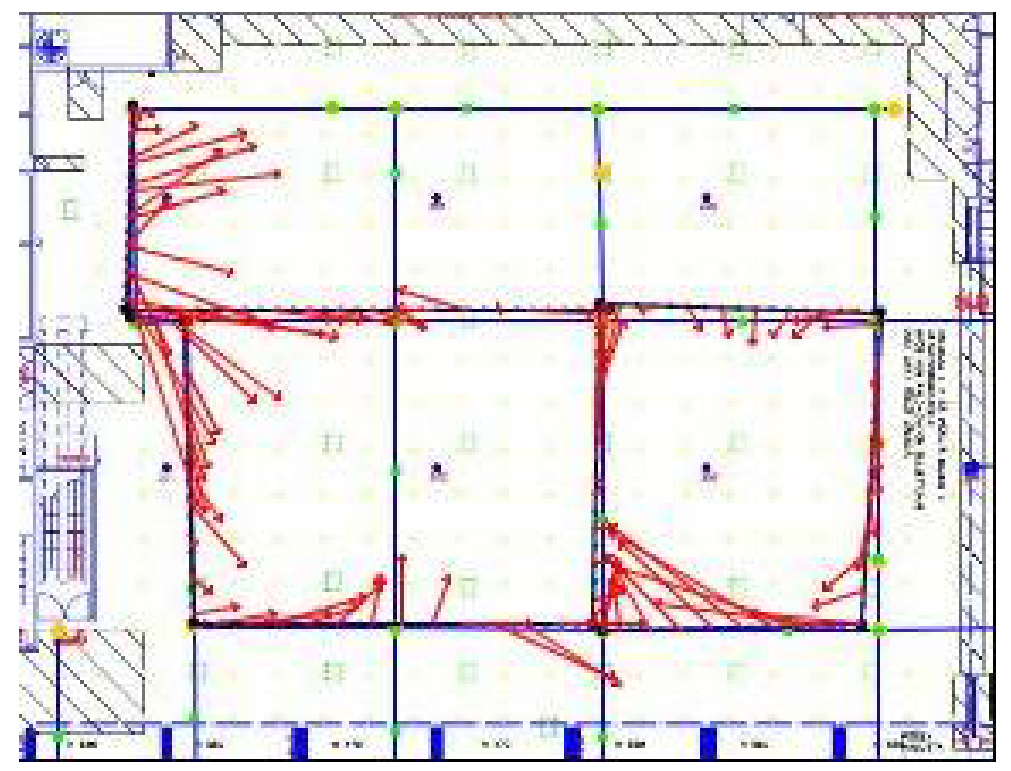

Fig. 3. Test User Walking Paths - Normal WLAN with high transmit power and low number of access points (FFC Exhibition Center)

\section{Conclusions and Further Research}

The evaluation trials have indicated that the WEG has achieved a high degree of overall acceptance. Despite some minor technical problems, mainly regarding the stability of the system in the case of multiple PDA users interacting with it in parallel sessions, all user groups were satisfied with the overall experience of having a personal exhibition guide, which provided them with navigation services and locationbased information. User feedback has been recorded in detail in order to feed future re-design and re-development efforts on the WEG technology and service solution. 
One of the primary innovative features of the WEG is the use of an indoor GPS system able to locate users with a quite great accuracy, compared to the positioning abilities of WLANs. The described indoor GPS solution has been implemented with the integration of a rather large module into the PDA device. Adding the GPS module has rendered the PDA device unacceptably large and has also significantly decreased its battery life. Future versions of the WEG should handle this problem by using either chipless GPS technology, which several device manufacturers are currently investigating, or a single chip that will handle all GPS functions [16]. Both GPS technology solutions will greatly contribute to minimizing both the power assumption and the size of the device to be used for accessing the WEG services.

Towards the purpose of convergence of voice and data services, the implementation of the same technology solution based on interconnection of wireless and mobile networks is proposed. The challenge concerns the provision of roaming services from mobile to wireless network and vice versa. To cover future inter-network roaming for users of wireless location-based services, an integrated location management architecture, much like the one proposed by Varshney [17], should be developed. Such architecture supports location tracking in other wireless networks (WLANs, PANs) as well as in cellular networks (GSM, GPRS) and satellites. The proposed solution would allow the WEG users to access multiple networks while being in the exhibition show, thus increasing the value of the WEG solution.

The current analysis of WEG business solution has triggered interest in analyzing the successful conditions, under which commercialization of WEG could be achieved. Based on alternative patterns of alliance formation, with the purpose of the WEG commercialization, among actors of the mobile and exhibition industry, a wide range of alternative business models can be identified and designed [18]. In practice, we expect that more than one business model for the exploitation of the WEG can apply given differences in the organizational and market conditions. We contend that the final selection/decision on the business model to be applied in a given situation will be based on a number of factors regarding both the internal and external environment of the candidate service providers, such as size, competitive position and corporate strategy (internal factors), but also competition degree, technology uncertainty, and market maturity (external factors).

\section{References}

1. UFI - The Global Association of the Exhibition Industry: Trade Fairs: A Powerful Marketing Tool (2004) [available online from: http://www.ufinet.org/, last accessed on: $9^{\text {th }}$ August 2004].

2. Munuera, J., Ruiz, S.: Trade Fairs as Services: A Look at Visitors Objectives in Spain. Journal of Business Research 44 (1999) 17-24.

3. Spaeth F.: The Extended-stay Exhibit. EXHIBITOR Magazine, November (2001) [available online from: http://www.exhibitornet.com/exhibitormagazine /article.asp?ID=66, last accessed on: $24^{\text {th }}$ April 2002].

4. Konopacki A.: New Trends In Exhibiting. Research Report (2002) [available online from: http://www.tradeshowresearch.com /pubs3/ntie.html, last accessed on $9^{\text {th }}$ August 2004].

5. Bieber, G., Giersich, M.: Personal mobile navigation systems - design considerations and experiences. Computers and Graphics 25 (2001) 563-570. 
6. Kraemer, R.: Bluetooth Based Wireless Internet Applications for Indoor Hot Spots: Experience of a Successful Experiment During CeBIT 2001. In: Proceedings of the $26^{\text {th }}$ Annual IEEE Conference on Local Computer Networks, November 14 - 16, Tampa - USA (2001)

7. Bianchi, A., Zancanaro, M.: Tracking users' movements in an artistic physical space. In: Proceedings of the I3 Second Annual Conference, October 20-22, Siena- Italy (1999)

8. Cox, D., Kindratenko, V., Pointer, D.: IntelliBadge ${ }^{\mathrm{TM}}$. In: Proceedings of the $1^{\text {st }}$ International Workshop on Ubiquitous Systems for Supporting Social Interaction and Face-toFace Communication in Public Spaces, 5th Annual Conference on Ubiquitous Computing - UbiComp 2003, October 12-14, Seattle - WA (2003) 41-47

9. Giaglis, G.M., Pateli, A., Fouskas, K., Kourouthanassis, P., Tsamakos, A.: On the Potential Use of Mobile Positioning Technologies in Indoor Environments. In: Loebbecke, C., Wigard, R.T., Gricar, J., Pucihar, A., Lenart, G. (eds.): Fifteenth Bled Electronic Commerce Conference - e-Reality: Constructing the eEconomy, June 17-19, Bled - Slovenia, Vol. 1. (2002) 413-429

10. Mathes I., Pateli A., Tsamakos, A., Spinellis, D.: Context aware services in an Exhibition Environment- the mEXPRESS approach. In: Stanford-Smith, B. et al. (eds.): Challenges and Achievements in E-business and E-work: Proceedings of the E-business and E-work Conference, October 16-18, Prague, The Czech Republic (2002) 685-692

11. Pateli, A., Spinellis, D., Giaglis, G.: Wireless Info-Communication and Navigation Services in Exhibition Shows. In: Horwitch, M. (eds.): PROCEEDINGS - The Third International Conference on M-Business - $\mathrm{m}>$ Business 2004, Uncovering the Next Waves - Major Opportunities and the Essential Lessons, July 12-13, New York - USA. (2004)

12. Tsilira, A., Pateli, A., Athanasiadis, E., Spinellis, D.: Targeted Messages in Indoor Mobile Environment: A Software-Oriented Approach. In: Proceedings of the IASTED International Conference on SOFTWARE ENGINEERING SE 2004, February 17-19, Innsbruck, Austria (CD- ROM Proceedings) (2004)

13. Davis, F.: Perceived Usefulness, Perceived Ease of Use, and User Acceptance of Information Technology. MIS Quarterly (1989) 319-340

14. Lee, W., Kim, T., Chung, J.: User Acceptance of the Mobile Internet. In: Proceedings of the First International Conference on Mobile Business, July 8-9, Athens - Greece (2002)

15. Mills, J.E., Morrison, A. M.: Measuring Customer Satisfaction with Online Travel. In: Proceedings of ENTER 2003 Conference, January 29-31, Helsinki - Finland (2003)

16. Kumar, S., Stokeland, J.: Evolution of GPS technology and its subsequent use in commercial markets. International Journal of Mobile Communications 1 (2003) 180-193

17. Varshney, U.: Location management for wireless networks: issues and directions. International Journal of Mobile Communications 1 (2003) 91-118

18. Maitland, C. F., Van de Kar, E. A. M, De Montalvo, U. W.: Network Formation for Provision of Mobile Information and Entertainment Services. In: Proceedings of the $16^{\text {th }}$ Bled Electronic Commerce Conference - eTrasformation, June 9-11, Bled - Slovenia (CD-ROM - Proceedings) (2003) 